\title{
A low profile compact three-way Wilkinson power divider with size reduction
}

\section{Ömer Kasar ${ }^{1}$}

\begin{abstract}
In this study, a three-way Wilkinson power divider (WPD) was proposed the circuit whose center frequency was selected as $1.9 \mathrm{GHz}$ operates between $0.95-2.95 \mathrm{GHz}$ frequencies and has a bandwidth of approximately $105 \%$. The simulation and measurement results of the designed circuit were well aligned with each other below $10 \mathrm{~dB}$ return loss and $13 \mathrm{~dB}$ isolation. In addition, 0.4, 0.3 and $1.0 \mathrm{~dB}$ insertion loss were obtained in the output ways, respectively. The circuit is made more compact thanks to the curved structure of the output ways. It has been found that the proposed three-way power divider takes about $35 \%$ less space than the conventional circuit design.
\end{abstract}

K e y w o r d s: Wilkinson power divider, size reduction, 3 way power divider, compact WPD

\section{Introduction}

In the microwave, the dimensions of the circuits that do the same work at different frequencies are different from each other. As an engineering requirement, broadband structures are preferred instead of designing individual circuits for each communication band. Thus, compact structures are produced that cover more communication bands and take up less space in the systems $[1,2]$. In electronics, at least three-way circuit elements that divide applied input power to the number of gates at the output are called power dividers. The Wilkinson Power Divider is the circuit that can make the power division lossless when the output ports are matched [3].

There are a lot of broadband WPD circuits in the literature [4-8]. Some studies have also been specifically designed to divide the input power into more than two output ways [9-15]. These generally include communication frequencies. However, in recent designs, microwave power divider circuits have focused on achieving higher bandwidth levels covering more frequency by performing lower return loss (RL), insertion loss (IL) and higher isolation (IS) analyses [16-22].

In this study, a WPD circuit was proposed which divides the input power into three equal ways (four ports). The length of each way was curved, so that the circuit takes up less space. The curvature of the transmission line reduces the area of the substrate material used and reduces the amount of free space on the structure. Therefore, a more compact circuit will be formed according to the frequency of operations.

In this article, the structure of the proposed three-way circuit is explained. The characteristics of the transmission lines in the output arms, impedance calculation and even-odd mode analysis, and the dimensions and properties of the circuit were given. Finally, the simulation (performed in ADS 2009) and the measurement results are compared.

\section{Design of three-way WPD}

The proposed design is a four-port Wilkinson power divider circuit, three of which are outputs. Schematic view of the circuit is in Fig. 1, where port 1 represents the single input port and ports 2,3 , and 4 are the output ports. The input power was divided along these branches. The distance of each output arm is a quarter wavelength $(l=\lambda / 4)$. The characteristic impedance of the transmission line in each branch where the power drops to one third is $Z_{1}=86.6 \Omega$ calculated from (1), [3]. The width of the line according to the characteristic impedance is $W_{L}=0.97 \mathrm{~mm}$. The transmission line on all ports is $Z_{0}=50 \Omega$ and its width is $W_{0}=2.9 \mathrm{~mm}$.

$$
Z_{1}=Z_{0} \sqrt{3} .
$$

There are two isolation resistors between the output ter-

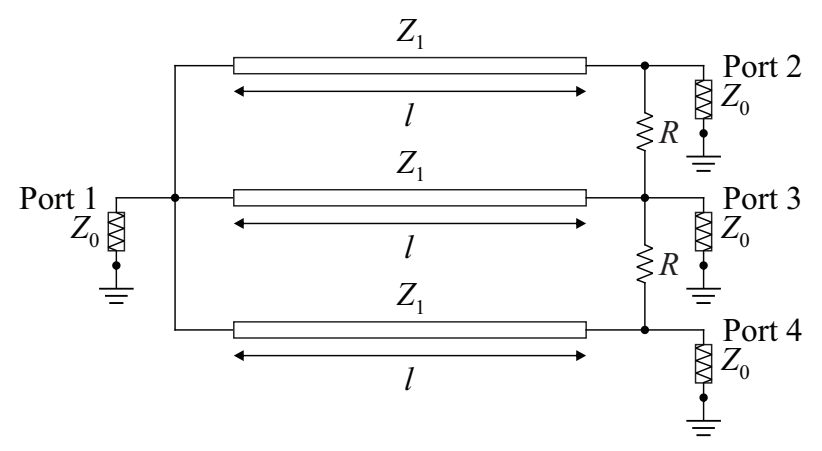

Fig. 1. Schematic view of three-way WPD

minals. The calculation of these two resistor was made by even-odd mode analysis according to (2)

$$
R=r_{e}+r_{0} .
$$

Artvin Çoruh University, Department of Electrical and Electronics Engineering, Artvin, Turkey, omerkasar@artvin.edu.tr 

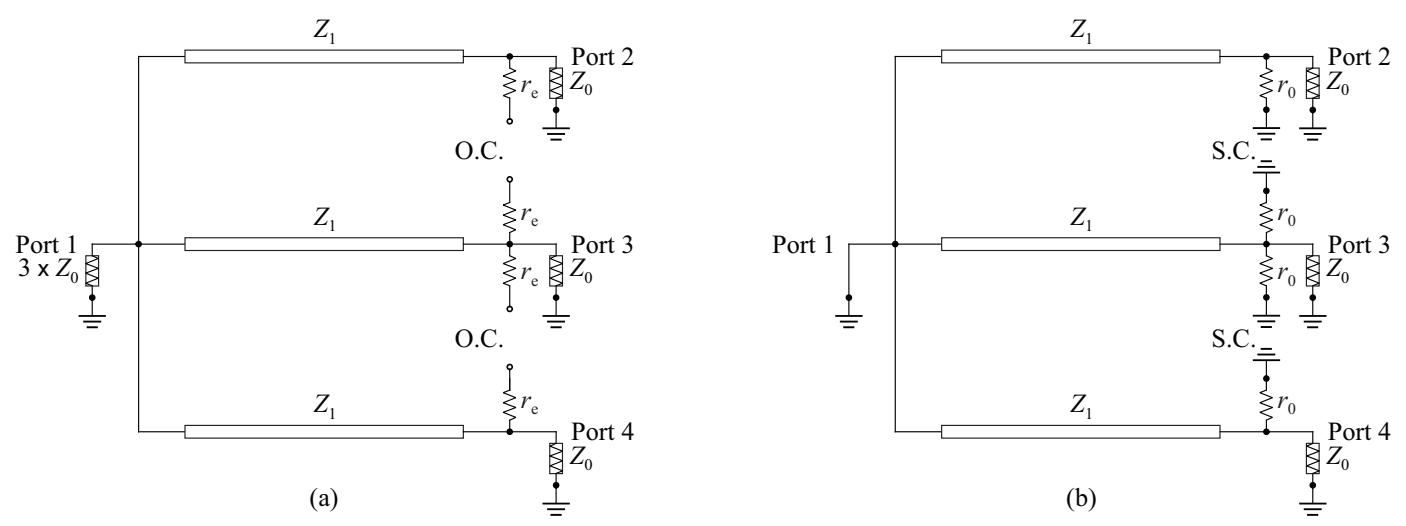

Fig. 2. even (a) and odd (b) mode analysis of three-way WPD

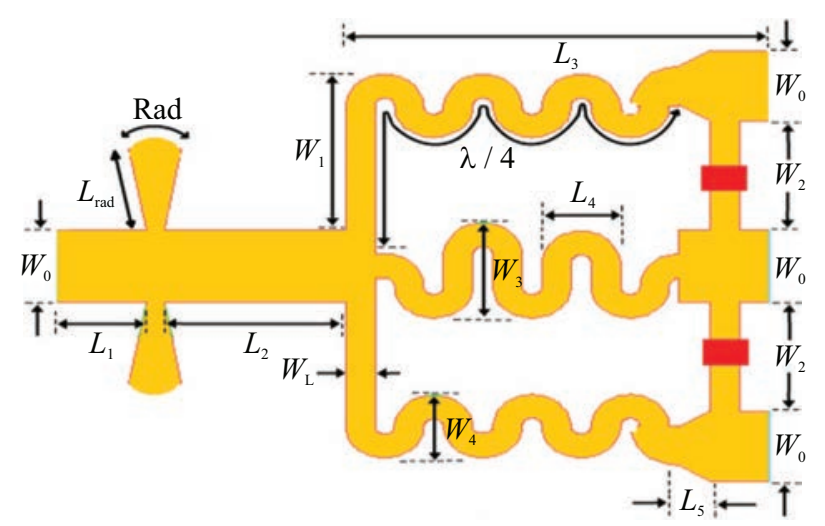

Fig. 3. Inner dimension of proposed threeway WPD

In even mode calculation, the transmission lines $Z_{1}$ were open circuited (OC). Since all outputs are equal split, the source impedance calculation seen at the input is $3 Z_{0}$. Figure $2($ a) shows the even mode equivalent circuit model. The resistors ended the transmission lines $\left(r_{e}\right)$ are actually not affect the isolation resistors value. In odd mode calculation, the input was short-circuited. The $r_{e}$ resistors are placed at the end of the matching sections $\left(Z_{1}\right)$. The odd mode equivalent circuit of the WPD design is shown in Fig. 2(b) [3,8]. Eventually, the isolation resistors were calculated to be $120 \Omega$.

In this study, the line impedance and lengths of the three-way were designed to be equal. The first and third ways are symmetrical to each other. In addition, the length of the second branch was slightly more curved than the others so that it can have the same length as the other ways. This curve affects the length $L^{\prime}$ of the circuit. If there were no folds provided that the width of the circuit remains the same (due to the butterfly stub), the length of the circuit would be $L^{\prime}=L_{1}+L_{2}+L_{5}+\lambda / 4+L_{p}$. Here, $L_{p}$ is the output point to which the connectors were combined. Thus, approximately $35 \%$ of space has been saved in the current situation.

Ideally, in a three-way WPD with equal power division, approximately $-4.77 \mathrm{~dB}$ of power can be transmitted to each way from the input port [3]. In non-ideal circuits, insertion loss (IL) occurs, [23] $I L=S_{i 1}-4.77$ where $S_{i 1}$, is the transmission parameter of each output port, and $i=2,3$, and 4 respectively.
To ensure wide band operation and impedance compatibility, butterfly stub was placed at the input of the divider. The dimensions of the stub with length $L_{\mathrm{rad}}=5$ $\mathrm{mm}$ and angle $\operatorname{Rad}=20^{\circ}$ were determined by parameter sweep. The internal dimensions of the design were given in Fig. 3.
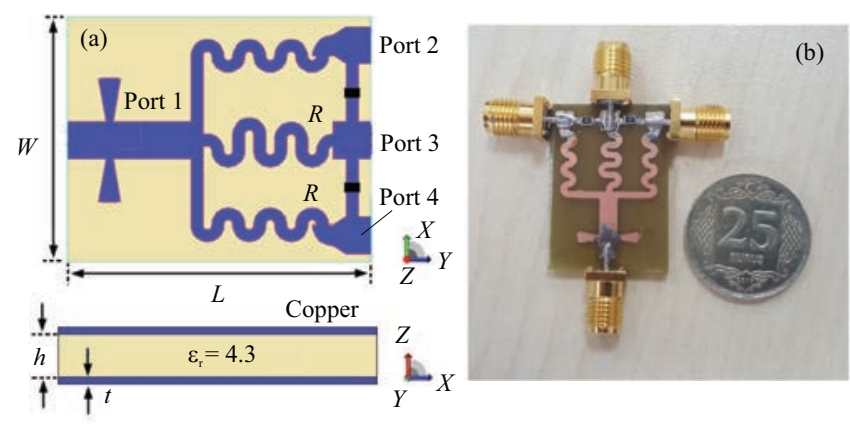

Fig. 4. Circuit: (a) - substrate outer dimensions, and (b) - manufactured circuit

In the three-way WPD circuit, the center frequency was selected as $f_{0}=1.9 \mathrm{GHz}$. The electrical permittivity of the FR4 substrate material is $\varepsilon_{r}=4.3$ and the tangential loss $\tan (\delta)=0.025$. The thickness of the material is $1.5 \mathrm{~mm}$. At the frequency $f_{0}$, the length of each layer selected in the quarter wavelength was calculated as $l=\lambda / 4=22 \mathrm{~mm}$. The external dimensions of the design and the manufactured circuit were shown in Fig. 4. All dimension, length and numerical values of the design were listed in Tab. 1 . The lengths of the circuit according to wavelength are $0.272 \times 0.215 \lambda^{2}$.

\section{Simulation and measurement}

The simulation and measurement results of the threeway WPD circuit $S_{11}, S_{22}, S_{33}$, and $S_{44}$ were shown in Fig. 5 and Fig. 6. The frequencies in which the return loss $(\mathrm{RL})$ is $10 \mathrm{~dB}$ or less on all gates are in the range $B W=0.95-2.95 \mathrm{GHz}$. According to these frequencies, Fractional Bandwidth (FBW) of $105 \%$ is achieved.

During BW, the average insertion losses were $I L_{S_{21}}=0.4 \mathrm{~dB}, I L_{S_{31}}=0.3 \mathrm{~dB}$, and $I L_{S_{41}}=1.0$ due to the transmission parameters $S_{21}, S_{31}$, and $S_{41}$ 


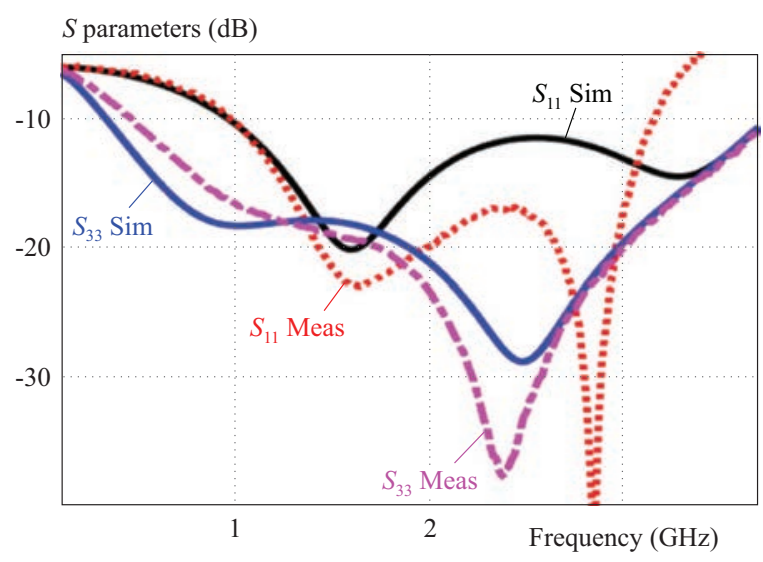

Fig. 5. Return losses of and

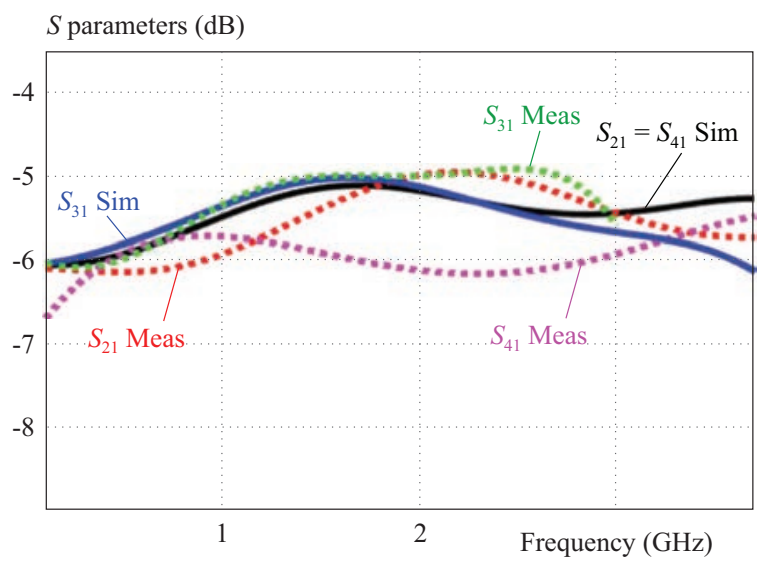

Fig. 7. Insertion losses of output ports

could not meet the ideal conditions. The transmission parameters and IL graphs are given in Fig. 7. The graph of the parameters $S_{32}, S_{42}$, and $S_{43}$, which are the isolation between the ports (IS) were shown in Fig. 8. The fact that the middle arm is not symmetrical with the other ways affected the isolation slightly. Nevertheless, it is possible to mention about $13 \mathrm{~dB}$ isolation in the $\mathrm{BW}$ range.

Table 1. Parameters

\begin{tabular}{lccc}
\hline Param. & Value & Param. & Value \\
\hline$L$ & $24 \mathrm{~mm}$ & $W_{0}$ & $2.9 \mathrm{~mm}$ \\
$W$ & $19 \mathrm{~mm}$ & $W_{1}$ & $6.4 \mathrm{~mm}$ \\
$h$ & $1.5 \mathrm{~mm}$ & $W_{2}$ & $4.5 \mathrm{~mm}$ \\
$t$ & $35 \mu \mathrm{m}$ & $W_{3}$ & $4 \mathrm{~mm}$ \\
$\varepsilon_{r}$ & 4.3 & $W_{4}$ & $2.6 \mathrm{~mm}$ \\
$R$ & 120 & $L_{1}$ & $3 \mathrm{~mm}$ \\
$\lambda / 4$ & 22 & $L_{2}$ & $6 \mathrm{~mm}$ \\
$\operatorname{Rad}$ & 20 & $L_{3}$ & $13.7 \mathrm{~mm}$ \\
$L_{\mathrm{rad}}$ & $5 \mathrm{~mm}$ & $L_{4}$ & $2.5 \mathrm{~mm}$ \\
$W_{\mathrm{L}}$ & $0.97 \mathrm{~mm}$ & $L_{5}$ & $1 \mathrm{~mm}$ \\
\hline
\end{tabular}

In the proposed three-way WPD circuit, in terms of simulation and measurement results, return loss (RL) and insertion loss (IL) are quite low, and its isolation (IS) is quite high. Table 2 shows the superiority of three-way WPD over previous studies. Graphs of S parameters gave

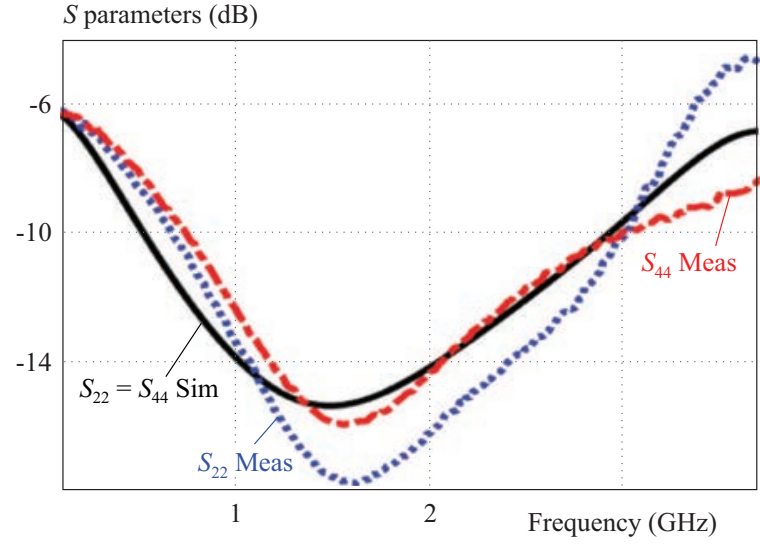

Fig. 6. Return losses of and

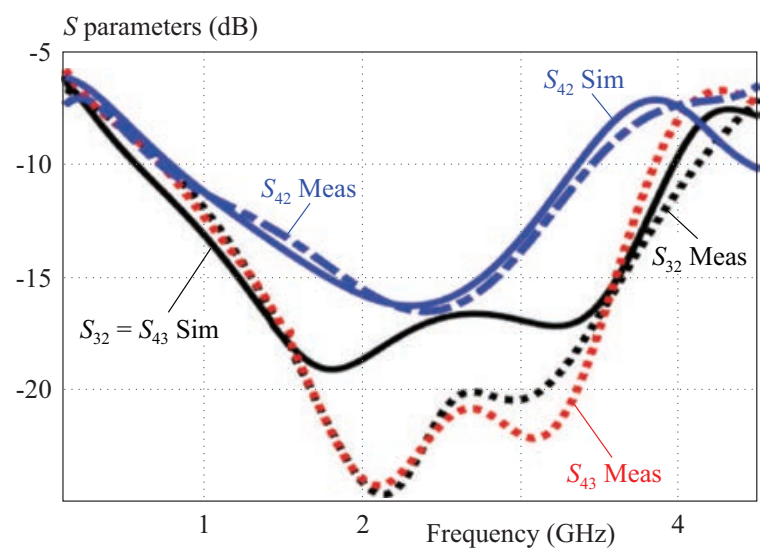

Fig. 8. Isolation between output ports

similar results to other studies in the literature. In addition, a very large fractional bandwidth $(\mathrm{FBW}=105)$ is an important feature that highlights the proposed threeway WPD. The three-way WPD has $35 \%$ smaller in size compared to the conventional design It can be said that it is a compact structure in terms of the area it covers according to the frequencies it operates. The best advantage of compact WPD is that the area covered in terms of dimensions $\left(\mathrm{mm}^{2}\right)$ and wavelength $\left(\lambda^{2}\right)$ is ahead of the examples in the literature.

\section{Concluson}

In this study, a three-way WPD circuit was designed. The WPD operating in the broadband range has been chosen as the center frequency of $1.9 \mathrm{GHz}$ to cover more communication bands. The WPD circuit provided about $105 \%$ fractional bandwidth at frequencies of $B W=$ $0.95-2.95 \mathrm{GHz}$ where it operates. Simulation and measurement results were in good agreement with each other. In terms of simulation and measurement performance, return loss (RL) and insertion loss (IL) are quite low, and its isolation is quite high.

An important advantage of the design is its small space. In this respect, the design is compact. It can be said that the curved structure of the ways for the purpose of size reduction provide better performance than the studies in the literature according to their sizes. The fact that 
Table 2. Comparison with previous works

\begin{tabular}{llccccccc}
\hline Reference & \multicolumn{1}{c}{ Method } & $\begin{array}{c}f_{0} \\
(\mathrm{GHz})\end{array}$ & $\begin{array}{c}\mathrm{RL} \\
(\mathrm{dB})\end{array}$ & $\begin{array}{c}\mathrm{IL} \\
(\mathrm{dB})\end{array}$ & $\begin{array}{c}\text { IS } \\
(\mathrm{dB})\end{array}$ & $\begin{array}{c}\text { FBW } \\
(\%) \text { or } * \mathrm{BW}\end{array}$ & $\begin{array}{c}\text { Size } \\
(\mathrm{mm})\end{array}$ & $\begin{array}{c}\text { Size } \\
\left(\lambda^{2}\right)\end{array}$ \\
\hline$(21)$ & Gysel power divider & 3.45 & 20 & 0.32 & 24 & 20.3 & - & large \\
$(9)$ & Band pass power divider & 3 & 10 & - & 15 & 49.4 & - & $0.50 \times 0.50$ \\
$(13)$ & Filtering power divider & 1.36 & 19.5 & $0.4 \mathrm{~min}$ & 11.6 & 57.3 & - & $0.568 \times 0.327$ \\
$(10)$ & Unequal split WPD & 7 & 10 & - & 10 & $*_{2}-12 \mathrm{GHz}$ & $59.18 \times 11.81$ & $\begin{array}{c}\text { large } \\
\text { This work }\end{array}$ \\
\hline
\end{tabular}

* In the article given as Bandwidth, - Not mentioned in the article

the proposed three-way WPD circuit covers many communication bands indicates its high usability in power division or combining applications.

\section{REFERENCES}

[1] Ö. Kasar, M. Kahriman, and M. A. Gozel, "Application of ultra wideband RF energy harvesting by using multisection Wilkinson power combiner," International Journal of RF and Microwave ComputerAided Engineering, vol. 29, no. 1, pp. 1-8, 2019.

[2] Y. Wu, Y. Liu, Q. Xue, S. Li, and C. Yu, "Analytical design method of multiway dual-band planar power dividers with arbitrary power division," IEEE Transactions on Microwave Theory Techniques, vol. 58, no. 12, pp. 3832-3841, 2010.

[3] M. Pozar, Microwave Engineering, 3rd ed. New York, USA: Wiley, 2006.

[4] K. M. Cheng and C. Law, "A novel approach to the design and implementation of dual-band power divider," (in English), IEEE Trans. Microw. Theory Tech., Article vol. 56, no. 2, pp. 487-492, Feb 2008, doi: 10. 1109/tmtt. 2007. 914629.

[5] J. Kim and Y. Lee, "A Z-Transform Method for Synthesis of Unequal-Length Multisection Transmission Lines for Multiband Applications," IEEE Transactions on Microwave Theory and Techniques, vol. 65, no. 9, pp. 3200-3210, 2017.

[6] S. Kumar and M. Kumar, "Ultra wide band Wilkinson equal power divider using rectangular rings of different impedance,", International Conference on Medical Imaging, m-Health and Emerging Communication Systems (MedCom), 2014, pp. 49-57.

[7] A. Belen, P. Mahouti, F. GNE, and H. Partal, "Design and Implementation of Doppler Microwave Motion Sensor for Indoor Application," Sigma Journal of Engineering and Natural Sciences, vol. 36, no. 3, pp. 849-859, 2018.

[8] Ö. Kasar, M. Kahriman, and M. A. Gözel, "A New Multi Stepped Real Impedance Matching Method with Euler Polynomials and its Application on Transmission Line," Journal of Engineering Sciences and Design, vol. 5, no. 3, pp. 547-552, 2017.

[9] S. Gao, S. Sun, and S. Xiao, "A novel wideband bandpass power divider with harmonic-suppressed ring resonator," IEEE Microwave Wireless Components Letters, vol. 23, no. 3, pp. 119-121, 2013.

[10] D. Hawatmeh, K. Al Shamaileh, N. Dib, and A. Sheta, "Design and analysis of a 3-way unequal split ultra-wideband Wilkinson power divider," International Journal of Electronics, vol. 100, no. 8, pp. 1062-1071, 2013.

[11] Y.-A. Lai, C.-M. Lin, J.-C. Chiu, C.-H. Lin, and Y.-H. Wang, "A compact Ka-band planar three-way power divider," IEEE Microwave Wireless Components Letters, vol. 17, no. 12, pp. 840-842, 2007.

[12] H. Oraizi and A. Yousefi, "Optimum design of a wideband planar N-way fork power divider with arbitrary power division and input-to-output impedance matching," AEU-International Journal of Electronics Communications, vol. 79, pp. 83-93, 2017.
[13] C. Zhu, J. Xu, W. Kang, and W. Wu, "Microstrip multifunctional reconfigurable wideband filtering power divider with tunable center frequency, bandwidth, and power division," IEEE Transactions on Microwave Theory Techniques, vol. 66, no. 6, pp. 2800-2813, 2018.

[14] C. Zhu and J. Zhang, "Design of High-Selectivity Asymmetric Three-Way Equal Wideband Filtering Power Divider," IEEE Access, vol. 7, pp. 55329-55335, 2019.

[15] L. Wang et al, "An on-Chip Planar Broadband 3-Way Power Divider for Josephson Voltage Circuits," IEEE Transactions on Applied Superconductivity, vol. 31, no. 1, pp. 1-4, 2020.

[16] H. Eghlidi, K. Mehrany, and B. Rashidian, "Analytical approach for analysis of nonuniform lossy/lossless transmission lines and tapered microstrips," IEEE Transactions on Microwave Theory and Techniques, vol. 54, no. 12, pp. 4122-4129, 2006.

[17] D. Hawatmeh, N. Dib, and K. Alshamaileh, "Microstrip Non-uniform Transmission Lines Triple Band 3-way Unequal Split Wilkinson Power Divider," Revue Roumaine Des Sciences Techniques-Serie Electrotechnique Et Energetique, vol. 62, no. 3, pp. 288-293, 2017.

18] X. Wang, I. Sakagami, A. Mase, and M. Ichimura, "Trantanella Wilkinson power divider with additional transmission lines for simple layout," IET Microwaves, Antennas \& Propagation, vol. 8, no. 9, pp. 666-672, 2014.

19] Y.-H. Pang and Z.-H. Li, "Dual-band bandpass Wilkinson power divider of controllable bandwidths," Electronics Letters, vol. 52, no. 7, pp. 537-539, 2016.

[20] V. Tas and A. Atalar, "An optimized isolation network for the Wilkinson divider," IEEE Trans. Microw. Theory Tech, vol. 62, no. 12, pp. 3393-3402, 2014.

[21] H. Chen, Y. Zhou, T. Zhang, W. Che, and Q. Xue, "N-Way Gysel Power Divider With Arbitrary Power-Dividing Ratio," IEEE Trans. Microw. Theory Tech., vol. 67, no. 2, pp. 659-669, 2018.

[22] P. Mahouti, M. A. Belen, H. P. Partal, S. Demirel, and F. Gúnes, "Miniaturization with dumbbell shaped defected ground structure for power divider designs using Sonnet," in 2015 31st International Review of Progress in Applied Computational Electromagnetics (ACES), 2015: IEEE, pp. 1-2.

23] P. Singh, S. Basu, and Y.-H. Wang, "Coupled line power divider with compact size and bandpass response," Electronics letters, vol. 45 , no. 17 , pp. 892-894, 2009.

Received 14 October 2020

Ömer Kasar received his BE degree in Electronics and Communication Engineering in Süleyman Demirel University, Isparta, Turkey in 2011, and then received MSc and PhD degrees in 2015 and 2019 respectively in the same university. He is currently an Assistant Professor in Department of Electrical and Electronics Engineering in Artvin Çoruh University, Turkey. His research interests include Microwave active and passive circuits design, Broadband impedance matching, RF Energy Harvesting and Frequency Selective Surfaces. 